3. Hoàng Thị Phúc, Phạm Trọng Văn, Nguyễn Hữu Quốc Nguyên (2010), Nghiên cứu tình hình bệnh võng mac đái tháo đường tại Việt Nam, Kỷ yếu hội nghị Nhã̃n khoa, 170.

4. Li $L$, Zhang $X$, Li $Z$, Zhang $R$ (2017), Renal pathological implications in type 2 diabetes mellitus patients with renal involvement, J Diabetes Complication, 31(1):114-121.

5. Shimin Jiang, Tianyu Yu, Zheng Zhang, et al (2019), Dianostic Performance of retinopathy in the detection of Diabetic nephropathy in Type 2 diabetes: A systematic review and meta-analysis of 45 studies, Ophthalmic Research, 2019, 62: 68-79
6. K Viswanath MS, Murray Mc Gavin (2013), Diabetes retinopathy: Clinical findings and management, Community Eye Health, Vol 16 No.46, pp.21-24.

7. Trần Thi Thu Hiên (2008), Nghiên cứu biến chứng trền mắt bệnh nhân đái tháo đường tại bệnh viện Mắt Trung ương, Luận văn thạc sĩ Y học, trường Đ̇ai hoc Y Hà Nội.

8. Lê Thị Hiền (2020), Mô tả đặc điểm lâm sàng, cân lâm sàng bệnh võng mac đái tháo đường tai bềnh viên đa khoa tỉnh Hòa Bình năm 2020 và mổt sổ yếu tố liên quan, Luận văn chuyên khoa cấp 2 , Trường đại học Y Hà Nội.

\title{
THỰC TRANG Dự TRŨ Cơ SỐ CHIẾN THƯƠNG VÀ PHÒNG CHỐNG DİCH BỆNH TẠI MộT SỐ BỆNH VIỆN QUÂN Y
}

\author{
Phạm Ngọc Bình*, Nguyễn Sơn Nam*, Chu Tiến Cường**
}

\section{TÓM TẮT}

Mục tiêu: Đánh giá thực trạng dự trữ một số cơ số chiến thương và phòng chống dịch bệnh tại một số bệnh viện quân y tuyến chiến lược và chiến dịch, năm 2016. Phương pháp: Phỏng vấn trực tiếp cán bộ quản lí bằng phiếu hỏi thiết kễ sẵn kểt hợp quan sát trưc tiếp các loai cơ số thuốc đang dự trữ tại bệnh viện; Chọn 8 bệnh viện quân y (4 bệnh viện tuyến chiến dịch, 4 bệnh viện tuyến chiến lược, khu vực tuyến chiến lược); mối bệnh viện chọn 2 cán bộ quản lí công tác dược, tổng số 16 cán bộ. Kết quả: Dự trữ cơ số K: có 4 bệnh viện có dự trữ; dự trữ cơ số BV: cả 8 bệnh viện đều có dự trữ; cơ số phòng chống dịch bệnh: có 2/8 bệnh viện có dự trữ. Tất cả các cơ số (K, BV) đã được thành lập tại các bệnh viện đều để mớ, có danh mục và bao bì để sẵn. Riêng cơ số phòng chống dịch bệnh tại 2 bệnh viện đã được đóng gói sẵn là các cơ số được cấp từ trên xuống. Cả 8 bệnh viện đều có khả năng luân lưu đổi hạn các cơ số Ý, K, BV và cơ số phòng chống dịch bệnh. Có 2 bệnh viện đủ khả năng luân lưu đổi hạn với số lượng cơ số chiến thương lớn; các bênh viển còn lại đủ khả năng luân lưu đổi han một số lượng nhất định các cơ số chiến thương và̀ phòng chống dịch bệnh. Kết luâan: Số lượng cơ số quân y dự trữ tại 8 bệnh viện phù hợp với chỉ tiêu nhiệm vụ được giao của các đơn vị. Tất cả các cơ số $B V, K$ dự trữ tại các bệnh viện đều để mở và có danh mục, có bao bì để sẵn (không đóng gói sẵn). Cả 8 bệnh viện đều có khả năng luân lưu đổi hạn các cơ số $Y, K, B V$ và cơ số phòng chống dịch bệnh.

Tư khóa: Bệnh viện quân y, cơ sỗ, dự trữ.

\section{SUMMARY}

\section{THE CURRENT STATUS OF THE BATTLE OF}

*Bệnh viện Trung ương Quân đội 108

**Cục Quân y

Chịu trách nhiệm chính: Phạm Ngọc Bình

Email: ngocbinh108@gmail.com

Ngày nhận bài: 12.5.2021

Ngày phản biên khoa hoc: 28.6.2021

Ngày duyệt bài: 13.7.2021

\section{BATTLE AND EVIDENCE PREVENTION AT} SOME MILITARY HOSPITAL

Objectives: Evaluation of the actual situation of stockpiling some battle facilities and disease prevention at some strategic and campaign-line military hospitals, 2016. Methods: Direct interviews with managers using pre-designed questionnaires combined with direct observation of drugs in stock at the hospital; Select 8 military medical hospitals (4 campaign hospitals, 4 strategic hospitals, strategic areas); Each hospital chooses 2 pharmacy managers, a total of 16 staff. Result: Base K reserve: there are 4 hospitals with reserve; hospital base reserve: all 8 hospitals have reserves; epidemic prevention base: $2 / 8$ hospitals have reserves. All facilities (K, BV) that have been established in hospitals are open, with catalogs and packaging available. Particularly, the epidemic prevention and control facilities at the two hospitals that have been prepackaged are those provided from the top down. All 8 hospitals have the ability to rotate the $\mathrm{Y}, \mathrm{K}, \mathrm{BV}$ radix and disease prevention radix. There are 2 hospitals capable of rotating and changing terms with a large number of casualties; the remaining hospitals are capable of rotating a certain number of battle facilities and disease prevention. Conclusion: The number of military medical facilities in reserve at 8 hospitals is in line with the units' assigned task targets. All BV and K facilities stocked at hospitals are open and have a list and ready-made packaging (not pre-packaged). All 8 hospitals have the ability to rotate the $Y, K, B V$ radix and disease prevention radix.

Keywords; Military hospital, base, reserve.

\section{I. ĐẶT VẤN ĐỀ}

Cơ số chiến thương (CSCT) là cơ số dùng để cứu chữa người bị thương, bị nạn được ký hiệu là cơ số $Y, K, B V . .$. Cơ số phòng chống dịch bệnh (PCDB) là cơ số để cứu chữa những người bị bệnh do dịch bệnh. Cơ số là một số lượng vật tư y tế (VTYT) được tính toán đồng bộ, đóng gói sẵn trong bao bì thích hợp, đủ cung cấp VTYT 
cho môt nhiệm vụ xác định hoăc trang bi cho một tổ chức quân y với nhiệm vụ theo quy định [6]. Để phù hợp với từng nội dung nhiệm vụ, mổi cơ số quân y tương ứng có kí hiệu, tên gọi riêng và được coi là đớn vị tính toán trong việc lập kế hoạch tiếp tế quân y hoặc trong đăng kí, thống kê, thanh toán... Một số loại CSCT là sản phẩm được hình thành từ những yêu câu thực tiễn của các cuộc chiến tranh giải phóng và bảo vệ Tổ quốc, nhằm trang bị sẵn cho quân nhân, cho đơn vị các trang bị, vật tư, thuốc thiết yếu để quân nhân tự cứu mình, cứu giúp đồng đội, kể cả cứu người dân ngay khi bị thương, bị nạn [1], [2].

Trong hoạt động bảo đảm quân y (BĐQY), thuốc, hóa chất, VTYT tiêu hao sử dụng để cấp cứu, điều trị người bị thương, bị nạn thường được tính toán, đóng gói và mã hóa thành cơ số để cấp phát, tiếp tế cho các đơn vị trước, trong và sau khi thực hiện nhiệm vụ quân sự và còn để dự trữ sẵn sàng trong các tình huống khẩn cấp của các đơn vị quân đội. Qua các cuộc kháng chiến chống Pháp, chống Mỹ và chống lấn chiếm biên giới Tây Nam, phía Bắc đã khẳng định, tiếp tế quân y bằng cơ số là phương thức tiếp tế chủ yếu, hiệu quả trong điều kiện chiến tranh. Trong thời bình, một số loại cơ số cũng đã được nghiên cứu, xây dựng, bảo đảm sẵn sàng cho các phân đội và cơ sở quân y thực hiện nhiệm vụ khẩn cẩp, đột xuất, như phòng chống thiển tai, thảm họa (bão lụt, động đất, dịch bệnh, khắc phục sự cố, thảm họa...). Trong tác chiến phòng thủ khu vực tỉnh/thành phố, việc chủ động cơ sở vật chất hậu cần và bảo đảm các loại cơ số trong chiến tranh BVQY là rất cần thiết, y phù hợp với tình hình nhiệm vụ an ninh, quốc phòng trước mắt cũng như' lâu dài [3].

Trong hệ thống ngành Quân y, bên cạnh các hoạt động nghiệp vụ thường xuyên, các bệnh viện quân y (BVQY) tuyến chiến dịch và chiến lược còn được giao một số nhiệm vụ quan trọng khác, như tổ chức các phân đội, cơ sở quân y sẵn sàng làm nhiệm vụ đáp ứng các tình huống khẩn cấp. Song song với công tác kiện toàn tổ chức các phân đội quân y, huấn luyện và luyện tập thường xuyên, các BVQY còn phải luôn chuẩn bị sẵn sàng các cơ số bảo đảm đủ khả năng hoàn thành nhiệm vụ trong mọi tình huống. Vì vậy, nghiên cứu đánh giá công tác chuẩn bị, dự trữ các CSCT phục vụ nhiệm vụ khẩn cấp và các nhiệm vụ đột xuất khác tại các BVQY là rất có có ý nghĩa thực tiễn.

Mục tiêu nghiên cứu: "Đánh giá thực trạng dự trữ một số CSCT và PCDB tại một số BVQY tuyến chiến lược và chiến dịch, năm 2016".

\section{II. Đốl TƯợNG VÀ PHƯƠNG PHÁP NGHIÊN CỨU}

2.1. Đối tượng nghiên cứu. Mức độ dự trữ CSCT và cơ số thuốc PCDB của 8 BVQY tuyến chiến dịch và tuyến chiến lược, đóng quân trên địa bàn khu vực phía Bắc. Thời gian nghiên cứu: năm 2016.

\subsection{Phương pháp nghiên cứu}

- Thiết kế nghiên cứu: Nghiên cứu mô tả cắt ngang kết hợp nghiên cứu định lượng và định tính.

- Cõ̃ mẩu và chon mẫu: chon chủ đích 8 BVQY (gồm 4 BVQY tuyến chiến dịch; 2 BVQY tuyến chiến lược khu vực và 2 BVQY tuyến chiến lược); mỗi BVQYY chọn 2 cán bộ quản lí công tác dược (1 đồng chí là phó giám đốc phụ trách công tác dược, trang bị và 1 chỉ huy khoa Dược), tổng số: 16 cán bộ.

- Nội dung nghiên cứu:

+ Một số đặc điểm tổ chức và nhiệm vụ BVQY.

+ Số lượng, thực trạng các CSCT và PCDB đang dự trữ.

+ Đánh giá về thuận lợi, khó khăn trong thực hiện dự trữ CSCT và PCDB tại BVQY.

- Phương pháp, kĩ thuật thu thập số liệu:

+ Quan sát trực tiếp các loại CSCT và PCDB đang dự trữ tại BVQY.

+ Phỏng vấn trực tiếp cán bộ quản lí bằng phiếu hỏi thiết kế sắn.

- Phân tích và xử lí số liệu: làm sạch phiếu điều tra và nhập số liệu, tính toán, xử lí số liệu bằng phương pháp thống kê y sinh thông thường.

\section{KẾT QUẢ NGHIÊN CỨU}

\subsection{Một số đặc điểm BVQY nghiên cứu:}

- Phân hạng bệnh viện:

+ Bệnh viênn hạng đặc biệt: 1 BVQY.

+ Bểnh viện hạng I: 7 BVQY.

- Số giường bệnh: các BVQY có từ 200-1.260 giường bệnh, trong đó:

+ Có 200-250 giường bênh: 5 BVQY.

+ Có 350-550 giường bệnh: 2 BVQY.

+ Có trên 1.000 giường bệnh: 1 BVQY.

- Đặc điểm nhiệm vụ:

+ Nhiệm vụ thường xuyên: các BVQY nghiên cứu đều thực hiện nhiệm vụ thu dung, điều trị, chăm sóc sức khỏe bộ đội và các đối tượng chính sách theo quy định; tham gia khám chữa bệnh bảo hiểm y tế và dịch vụ y tế cho nhân dân. BVQY hạng đặc biệt còn có nhiệm vụ tham gia bảo vệ, chăm sóc sức khỏe cán bộ cao cấp của Đảng, Nhà nước và làm nhiệm vụ quốc tế. 1 BVQY có một số chuyên khoa tuyến cuối toàn quân. 6 BVQY còn lại là các bệnh viện khu vực tuyến chiến lược và tuyến chiến dịch.

+ Nhiệm vụ liên quan đến dự trữ cơ số quân 
y tại chỗ: các BVQY nghiên cứu đều được giao tổ chức, huấn luyện, sẵn sàng triển khai các phân đội quân y và cơ sở quân y có liên quan đến dự trữ các loại cơ số để bảo đảm cứu chữa người bị thương, bị nạn.

\subsection{Thực trạng các cơ số quân y SSCĐ} và PCDB dữ trữ:

- Các CSQQY dự trữ tại các BVQY nghiên cứu:

+ Cơ số K: có 4 BVQY đang có dự trữ theo quy định.

+ Cơ số BV: cả 8 BVQY đang có dự trữ theo quy định.

+ Cơ số PCDB: có 2 BVQY đang có dự trữ do trên cấp phát xuống.

Số lượng CSCT và PCDB dự trữ tại các BVQY nghiên cứu phù hợp với chỉ tiêu nhiệm vụ được giao của các đơn vị.

- Tình trạng CSCT và PCDB tại các BVQY nghiên cứu:

\begin{tabular}{|c|c|c|c|c|}
\hline \multirow[b]{2}{*}{$\begin{array}{c}\text { oại cơ } \\
\text { số }\end{array}$} & \multicolumn{4}{|c|}{ Tình trạng cơ số } \\
\hline & $\begin{array}{l}\text { Đã } \\
\text { đónng } \\
\text { sănn }\end{array}$ & $\begin{array}{l}\text { Để các mặt } \\
\text { hàng của } \\
\text { cơ số ở } \\
\text { dạng mở }\end{array}$ & $\begin{array}{l}\text { Có danh } \\
\text { mục các } \\
\text { mặt hàng } \\
\text { của cơ số }\end{array}$ & $\begin{array}{l}\text { Có bao } \\
\text { bì các } \\
\text { cơ số } \\
\text { để sẵn }\end{array}$ \\
\hline ơ số $\mathrm{K}$ & 0 & $x$ & $x$ & $x$ \\
\hline $\begin{array}{c}\text { Cơ số } \\
\text { BV }\end{array}$ & 0 & $x$ & $x$ & $x$ \\
\hline $\begin{array}{l}\text { Cơ SỐ } \\
\text { PCDB }\end{array}$ & 0 & $\mathrm{x}$ & $\mathrm{x}$ & $\mathrm{x}$ \\
\hline
\end{tabular}

Tất cả các cơ số $K$ và cơ số $B V$ đã được thành lập tại các BVQY nghiên cứu đều để ở dạng mở /hàng rời; có danh mục và bao bì để sẵn, không có cơ số nào được đóng gói sẵn. Riêng các cơ số PCDB tại 2 BVQY đã được đóng gói sẵn là các cơ số được cấp từ trên xuống.

Bảng 2. Khả năng luân lưu đổi hạn cơ số của các bệnh viện quân y

\begin{tabular}{|c|c|c|c|c|}
\hline \multirow{2}{*}{ BVQY } & \multicolumn{4}{|c|}{ Khả năng luân lưu, đối hạn các } \\
& \multicolumn{4}{|c|}{ loại CSQY } \\
\cline { 2 - 5 } & Y & K & BV & PCDB \\
\hline Thứ 1 & 40 & 20 & 10 & 2 \\
\hline Thứ 2 & 40 & 20 & 10 & 2 \\
\hline Thứ 3 & 1 & 1 & 1 & 1 \\
\hline Thứ 4 & 1 & 1 & 1 & 1 \\
\hline Thứ 5 & 1 & 1 & 1 & 1 \\
\hline Thứ 6 & 1 & 1 & 1 & 5 \\
\hline Thứ 7 & 1 & 1 & 2 & 2 \\
\hline Thứ 8 & 1 & 1 & 2 & 1 \\
\hline
\end{tabular}

Cả 8 BVQY nghiên cứu đều dự kiến có khả năng luân lưu đổi hạn các cơ số $Y, K, B V$ và cơ số PCDB. Trong đó, có 2 BVQY đủ khả năng luân lưu đổi hạn với số lượng cơ số SSCĐ lớn; các BVQY còn lại đủ khả nắng luân lưu đổi hạn từ 12 cơ số SSCĐ và từ 1-5 cơ số PCDB.

3.3. Thuân lợi và khó khăn trong dự trữ cơ số quân y tại bệnh viện: Khảo sát ý kiến 16 cán bộ quản lí công tác dược, trang bị về những thuận lợi, khó khăn và kiến nghị nâng cao chất lượng công tác dự trữ các cơ số tại các BVQY nghiên cứu, kết quả như sau:

Bảng 3. Thuận lợi, khó khăn và kiến nghị về công tác dự trữ cơ số.

\begin{tabular}{|c|c|c|}
\hline & Nội dung ý kiến & Số Iương \\
\hline & Có đủ điều kiện để thành lập, đóng gói các cơ số BV, K, Y.. & $16(100 \%)$ \\
\hline Thuận & Có đủ khả năng và điều kiện luân lưu đổi hạn thuốc với các cơ số BV, K, Y... & $16(100 \%)$ \\
\hline lợi & $\begin{array}{c}\text { Đã có danh mục thuốc, vật tư của các loại cơ số và đã được Cục Quân y } \\
\text { hướng dẫn đóng gói các loại cơ số }\end{array}$ & $16(100 \%)$ \\
\hline & $\begin{array}{c}\text { Một số loại thuốc có trong các cơ số nhưng ở BVQY không còn sử dụng } \\
\text { hoặc sử dụng nhưng rất ít (như thuốc mê, thuốc tê, thuốc chống quá mẩn, } \\
\text { thuốc trơ tim, trơ hô hấp, thuốc kháng sinh...) }\end{array}$ & $16(100 \%)$ \\
\hline $\begin{array}{l}\text { Khó } \\
\text { khăn }\end{array}$ & $\begin{array}{l}\text { Thiếu các văn bản hướng dần cụ thế về thay thế một số loại thuốc trong } \\
\text { danh mục quy định của cơ số mà BVQY không có hoặc khồng sử dụng }\end{array}$ & $16(100 \%)$ \\
\hline & $\begin{array}{l}\text { Cơ chế bảo đảm cho công tác thực hiện dự trữ cơ số tại các BVQY } \\
\text { chưa phù hợp }\end{array}$ & $8(50 \%)$ \\
\hline & $\begin{array}{l}\text { Cần quy định cụ thế cho các BVQY dự trữ các loại CSCT và PCDB về số } \\
\text { lượng, chủng loại và cơ chế đảm bảo, luân lưu đổi hạn }\end{array}$ & $16(100 \%)$ \\
\hline $\begin{array}{l}\text { Kiên } \\
\text { nghị }\end{array}$ & $\begin{array}{l}\text { Cân ban hành danh mục thuốc, vật tư của các loại cơ số phù hợp với } \\
\text { danh mục thuốc, vật tư của các BviQY đang sử dụng và hướng dần quy } \\
\text { trình, quy cách đóng gói, bảo quản, luân lưu đổi hạn. }\end{array}$ & $16(100 \%)$ \\
\hline
\end{tabular}

\section{BÀN LUÂ̂N}

- Về cơ sở giường bệnh, phân hạng bệnh viện và thực hiện nhiệm vụ thường xuyên: Trong số 8 BVQY nghiên cứu, có 1 bệnh viện hạng đặc biệt và 7 bệnh viện hạng I. Trong thời bình, các
BVQY nghiên cứu ngoài nhiệm vụ thu dung, điều trị, chăm sóc sức khỏe cho bộ đội, các đối tượng chính sách; còn tham gia khám chữa bệnh bảo hiểm y tế và dịch vụ y tế cho nhân dẩn. Trên thực tế, hằng năm, mỗi bệnh viện thu dung điều 
trị cho hàng trăm nghìn lượt bệnh nhân quân và dân. Do đó, nguồn thuốc, trang thiết bị y tế và hóa chất, VTYT sử dụng rất lớn, đa dạng, thường xuyên được cập nhật. Với đặc điểm này, các BVQY có nhiều thuận lợi để thành lập, đóng gói, bảo quản, dự trữ, luân lưu đổi hạn các loại cơ số theo yêu cầu nhiệm vụ.

- Về nhiệm vu sãn sàng đáp ứng các tình huống khẩn cấp và đột xuất: Cả 8 BVQY nghiên cứu đều được giao nhiệm vụ thành lập các phân đội quân y sẵn sàng cơ động làm nhiệm vụ. Ngoài ra, các BVQY tuyến chiến lược còn được giao nhiệm vụ thành lập các cơ sở quân y để sẵn sàng đáp ứng các tình huống khẩn cấp ở quy mô chiến dịch. Do đó, việc các BVQY chủ động chuẩn bị và dự trữ các cơ số để sẵn sàng thực hiện nhiệm vụ khi có tình huống hẩn cấp là yểu cầu khách quan và hết sức cần thiết.

- Về thực trạng công tác dự trữ CSCT và PCDB tại các BVQYY: Tại thời điểm nghiên cứu, cả 8 BVQY đều có dự trữ CSCT đầy đủ cả về chủng loại và số lượng theo quy định của trên [4]. Cụ thể, cả 8 BVQY đều có dự trữ cơ số BV; 4 BVQY có dự trữ cơ số $K$. Như vậy, còn 4 BVQY không dự trữ cơ số $\mathrm{K}$, trong khi các $\mathrm{BV}$ này đều được giao nhiệm vụ thành lập đội quân y có sử dụng cơ số K. Điều này cho thấy việc chuẩn bị, dự trữ các CSCT của các BVQY còn chưa được thống nhất. Tuy nhiên, tại thời điểm nghiên cứu cũng chưa có các văn bản quy định bắt buộc và hướng dẫn cụ thể.

- Về tình trang CSCT và PCDB dự trữ tại các BVQY: Thực tế tại 8 BVQY nghiên cứu cho thấy, tất cả các loại CSCT dự trữ đã được thành lập đều để ở dạng mở/hàng rời và có danh mục và bao bì để sẵn (không có cơ số nào được đóng gói sẵn). Riêng 2 BVQY có một số cơ số $P C D B$ được Bộ Y tế cấp thông qua Cục Quân y là đã được đóng gói sằn. Tuy nhiên, có thể các CSCT đã được để rời theo danh mục và chưa được đóng gói sẵn là để thuận tiện trong việc luân lưu, đổi hạn. Hơn nữa, khi có tình huống nhiệm vụ khẩn cấp, đột xuất cần huy động ngay cơ số thuốc, việc đóng gói các cơ số này đối với các BVQY tuyến chiến lược và chiến dịch vẫn đủ khả năng bảo đảm kịp thời. Thực tế, ở các BVQY nghiên cứu luôn sằn có các mặt hàng, chủng loại thuốc, VTYT lớn, phong phú về chủng loại; đồng thời, các BVQY luôn có nguồn nhân lực $y$, dược dồi dào, có trình độ chuyên môn lâm sàng và có kiến thức về y học quân sự vững vàng, có thể tham gia đóng gói các cơ số và hoàn thành trong thời gian ngắn nhất. Tuy nhiên, qua đây cũng cho thấy chưa có quy định thống nhất về quy cách cơ số dự trữ trong toàn quân, các BVQY cũng còn chưa thực hiện thống nhất quy định, hướng dẫn của trển về dự trữ cơ số là dự trữ theo hình thức cơ số mở (dự trữ đủ thuốc theo nội dung cơ số và để ở khu vực riêng, thuận lợi cho công tác luân lưu, đổi hạn...) [8]. Khi còn chưa có quy định rõ ràng, hướng dẫn cụ thể và kiểm tra chặt chẽ công tác chuẩn bị thì sẽ bị động về chuẩn bị cơ số trong các tình huống quân sự khẩn cấp.

- Về thực trạng khả năng luân lưu đổi hạn CSCT và PCDB dự trữ: Cả 8 BVQY nghiên cứu đều có khả năng luân lưu đổi hạn các cơ số $Y, K$, $B V$ và cơ số $P C D B$. Trong đó, năng lực luân lưu đổi hạn các cơ số dự trữ của 2 BVQY tuyến chiến lược là lớn nhất (đủ khả năng luân lưu đổi hạn hàng chục $c 0$ số $Y, K, B V$ và $P C D B$ ). Thực tế này cho thấy, các BVQY tuyến chiến lược và chiến dịch trong toàn quân không chỉ có đủ điều kiện và năng lực thành lập, dự trữ các loại cơ số thuốc phục vụ cho nhiệm vụ của chính bệnh viện mình, mà còn có khả năng luân lưu đổi hạn các loại cơ số cho các đơn vị quân đội trong khu vực.

- Về ý kiến đánh giá những thuận lợi, khó khăn và kiến nghị trong công tác thực hiện dự trữ cơ số tại BVQY: Có một số ý kiến về những khó khăn, bất cập trong công tác thực hiện dự trữ cơ số tại bệnh viện cần được các cơ quan chức năng xem xét, có hướng giải quyết cụ thể. Khó khăn đáng lưu ý, được $100 \%$ cán bộ quản lí cùng cho rằng: một số loại thuốc cụ thể có trong danh mục các CSCT, nhưng ở các BVQY không còn sử dụng hoặc sử dụng nhưng rất hạn chế (như một số loại thuốc mê, thuốc tê, thuốc chống quá mẫn, thuốc trợ tim, trợ hô hấp, thuốc kháng sinh...). Trên thực tế, từ năm 2008, Cục Quân y đã có văn bản hướng dẫn nguyên tắc, nội dung, phân cấp dự trữ và phương thức bảo đảm dự trữ vật chất, trang bị quân y bảo đảm nhiệm vu [5]. Năm 2009, Cục Quân y có văn bản hướng dẫn việc chuyển đổi, đóng mới cơ số $Y, K$, BV [8]. Năm 2012, Cục Quân y đã có kế hoạch bổ sung, thay thế nội dung cơ số thuốc dự trữ (hướng dẫn thay thế một số thuốc cụ thể trong danh mục thuốc cơ số BV) [9]. Như vậy, việc chỉ huy BVQY và chỉ huy khoa dược các BVQY nghiên cứu nêu ra các khó khăn trên là phù hợp với tình hình thực tế của các BVQY. Đây cũng là nhận định khách quan từ các nghiên cứu, báo cáo về CSCT trước đó.

\section{KẾT LUẬN}

- Cả 8/8 BVQY nghiên cứu đều có dự trữ cơ số BV; 4/8 BVQY có dự trữ cơ số $K$ và 2 BVQY có 
dự trữ cơ số PCDB.

- Tất cả các cơ số BV , cơ số K dự trữ tại các BVQY nghiên cứu đều để ở dạng mở và có danh mục và bao bì để sẵn, không có cơ số nào được đóng gói sẵn. Các cơ số PCDB dự trữ tại các BVQY đều được đóng gói sẵn và do trên cấp. Cả 8 BVQY nghiên cứu đều có khả năng luân lưu đổi hạn các cơ số $Y, K, B V$ và cơ số $P C D B$.

Từ kết quả nghiên cứu này, chúng tôi kiến nghị: cấp có thẩm quyền cần ra văn bản mới quy định thống nhất toàn quân về lượng dự trữ các loại cơ số; hướng dẫn chi tiết hớn về công tác quản lí, đóng gói, kiểm tra các loại cơ số. Đồng thời, giao nhiệm vụ cho các BVQY thành lập, dự trữ, luân lưu đổi hạn các loại cớ số Y, K, BV để phục vụ nhiệm vụ của bệnh viện mình và cho các đơn vị quân đội trong khu vực.

\section{TÀI LIÊU THAM KHẢO}

1. Lê Đình Cớn và cộng sự (2010). Nghiên cứu hoàn thiện cơ số thuốc và trang bị Quân y cho cá nhân, quân y đại đội và tiểu đoàn bộ binh để đảm bảo cứu chữa tb̉bb trong chiến tranhi BVTQ, Đề tài nghiên cứu cấp Bộ Quốc phòng (mã số
KCB.04.07.01).

2. Vương Bích Bình, Nguyễn Mạnh Quang (2010), Nghiên cứu hoàn thiên cơ số thuốc và trang bi quân y để bảo đảm cứu chữa bước đầu và cứu chữa cơ bản trong chiến tranh bảo vệ tổ quốc. Đề tài nghiên cứu cấp Bộ Quốc phòng (mã sỗ KCB.04.07.02)

3. Nguyễn Phi Long và công sự (2007). Nghiên cứu một số cơ số thuốc và̀ trang bị cho tuyến quân $\mathrm{e}$, f.. thời kỳ mới, Đề tài nghiên cứu cấp Bộ Quốc phòng.

4. Bộ Tổng Tham mưu (2012). Chỉ thị số 22/CTTM ngày 18/9/2012 V/v Điêu chỉnh dự trữ vật chất, trang bi hậu cần bảo đảm nhiêm vu khẩn cấp.

5. Cục Quân y (2008). Công văn số $640 / \mathrm{KH}-\mathrm{QY}$ ngày 07/4/2008 V/v thực hiện Chỉ lệnh 257/CL-HC của Chủ nhiệm Tống cục Hậu cần.

6. Cực Quân y (2015). Y họ̣c Quần sự - Nhà xuất bản Quân đối nhân dần, Hà Nôi - 2015.

7. Quân Đội nhân dân (2000). Điều lệ phòng chống dich - Nhà xuất bản Quân đội nhân dân, Hà Nội - 2015.

8. Cưc Quân y (2009). Công văn số $365 / O Y-D$ ngày 25/3/2009 V/v chuyển đổi, đóng mới cơ số $Y$, $K$, $\mathrm{BV}$ dự trữ tình huống khẩn cấp.

9. Cục Quân y (2012). Kế hoạch số $712 / K H-D$ ngày 28/5/2012 V/v Bổ sung thay thế nội dung cơ số thuốc dự trữ tình huống khẩn cấp.

\section{KẾT QUẢ ĐIỀU TRI SỎI THẬN BẰNG TÁN SỎI NộI SOI NGƯợC DÒNG VớI ỐNG MỀM CÓ SỬ DUUNG NĂNG LƯƠ'NG LASER HOLMIUM TẠI BÊ̂NH VIÊ̂N E}

\section{TÓM TẮT}

Mục tiêu: Đánh giá kết quả điều trị sỏi thân bằng nội sơi ngược dòng với ống mềm có sử dụng năng lương laser holmium tai Bênh viên $E$. Đối tướng và phương pháp nghiên cứu: Nighiên cứu sử dụng thiết kể mô tả cắt ngang kết hợp hồi cứu và tiến cứu $70 \mathrm{BN}$ sỏi thận có chỉ định điều trị bằng phương pháp tán sỏi nội soi ngược dòng sử dụng ống mềm tại khoa Thận - Tiết Niệu, Bệnh viện E trong khoảng thời gian từ $01 / 2020$ đến $5 / 2021$. Kết quả nghiên cứu: $90 \%$ BN đã sạch sỏi, 4,3\% BN còn mảnh vụn < $5 \mathrm{~mm}, 2,9 \%$ $\mathrm{BN}$ còn mảnh vụn $>5 \mathrm{~mm}$. 2,9\% BN còn sót sỏi. Biến chứng gặp phải là sốt sau mổ $(2,8 \%)$, đau do mảnh sỏi xuống niệu quản $(1,4 \%)$, nhiếm trùng tiết niệu $(1,4 \%)$. Số ngày dẫn lưu niệu quản trung bình là $22,97 \pm 6,75$ ngày, lớn nhất 35 ngày, ít nhất 4 ngày. Thời gian nằm viên sau mổ trung bình $5,2 \pm 3,7$ ngày, ngắn nhất là 2 ngày, dài nhất là 32 ngày.Thời gian nằm viện trung bình là $9,97 \pm 6,02$ ngày, ngắn

${ }^{1}$ Họ viên Quân y

Chịu trách nhiệm chính: Nguyễn Xuân Phúc

Email: nxp36a2003@gmail.com

Ngày nhận bài: 13.5 .2021

Ngày phản biên khoa học: 29.6.2021

Ngày duyệt bài: 13.7.2021

\section{Nguyễn Xuân Phúc ${ }^{1}$, Phạm Quang Vinh ${ }^{1}$}

nhất là 3 ngày, dài nhất là 45 ngày. $90 \%$ BN có kết quả điều trị tốt. 4,3\% BN có kết quả khá, và $5,7 \%$ BN có kết quả trung bình. Kết luận: Nội soi ống mềm bằng năng lượng laser holmium là phương pháp an toàn và hiệu quả điêu trị sỏi thận. Điều này cũng giúp cho phẫu thuật viên và bệnh nhân có thêm một lựa chọn trong điều trị nhằm đtạ hiệu quả cao và giảm biển chứng.

Tư khóa: Sỏi thận, nội soi ngược dòng, laser holmium

\section{SUMMARY}

\section{RESULTS OF KIDNEY STONE TREATMENT BY UPSTREAM ENDOSCOPY WITH SOFT TUBES USING HOLMIUM LASER ENERGY AT E HOSPITAL}

Objectives: To evaluate the results of kidney stone treatment by upstream endoscopy with soft tubes using holmium laser energy at $E$ hospital. Subjects and methods: The study used a crosssectional descriptive design combining retrospective and prospective 70 kidney stones patients with indications for treatment by retrograde endoscopic lithotripsy using flexible tubes at the Nephrology Department. - Urology, Hospital E during the period from January 2020 to May 2021. Results: $90 \%$ of patients were cleared of stones, $4.3 \%$ of patients had 